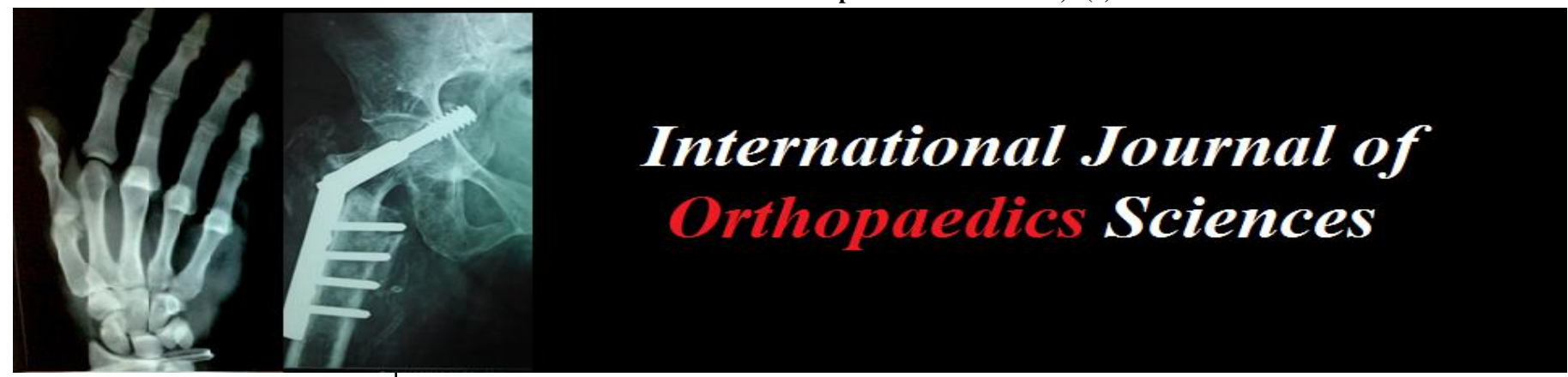

ISSN: $2395-1958$

IJOS 2018; 4(3): 184-188

(C) 2018 IJOS

www.orthopaper.com

Received: 04-05-2018

Accepted: 05-06-2018

Dr. Rajendra Ahire

Associate Professor, Pt JLN

Medical College, Raipur,

Chhattisgarh, Punjab, India

Dr. Saurabh Jindal

Assistant Professor, Pt JLN

Medical College, Raipur,

Chhattisgarh, Punjab, India

Dr. S Phuljhele

Professor, Pt JLN Medical

College, Raipur, Chhattisgarh,

Punjab, India

Dr. Narayan Dev Sahu

PG Student, Pt JLN Medical

College, Raipur, Chhattisgarh,

Punjab, India

Dr. Gautam Kashyap

Senior Registrar, Pt JLN

Medical College, Raipur,

Chhattisgarh, Punjab, India

Correspondence

Dr. Saurabh Jindal

Assistant Professor, Pt JLN

Medical College, Raipur,

Chhattisgarh, Punjab, India

\section{A comparative study between swashbuckler approach (Modified Anterior Approach) and lateral approach for the distal femur fractures}

\author{
Dr. Rajendra Ahire, Dr. Saurabh Jindal, Dr. S Phuljhele, Dr. Narayan \\ Dev Sahu and Dr. Gautam Kashyap
}

DOI: https://doi.org/10.22271/ortho.2018.v4.i3d.34

\section{Abstract}

Background: Distal femur fractures with intra-articular extension and comminution are challenging injuries, fraught with complications such as mal-union and stiffness. We prospectively evaluated and compared a consecutive series of patients with $\mathrm{AO}$ type $\mathrm{B}$ and $\mathrm{C}$ distal femur fractures to determine the clinico-radiological outcome after fixation with distal femur locking compression plate using Swashbuckler approach and standard lateral approach.

Materials and Methods: 60 patients with AO Muller's type B and C distal femur fractures (mostly type $\mathrm{C} 2$ and C3) were treated with distal femur locking compression plate (DF-LCP), 30 patients using swashbuckler approach and 30 patients using standard lateral approach. The regular follow-up up to 1 year was done and results were determined using the Neer's Score.

Results: All fractures united at a mean of 14.64 weeks (range 12-20 weeks). In our study mean duration of surgery for lateral approach group was greater (99.6min) than swashbuckler group (85 min). Mean ROM in swashbuckler group was 100.83 degree compared to 83.83 in lateral group. Mean Neer's score was 76.96 in lateral approach group compared to 81.83 in swashbuckler approach group. Complication rate was similar in both the group.

Conclusion: The results of distal femur fractures using a swashbuckler approach are encouraging and comparable to standard lateral approach with a majority of patients achieving good to excellent outcome at 1 year especially in complex AO type $\mathrm{C} 3$ fractures.

Keywords: Swashbuckler approach, standard lateral approach, distal femur locking compression plate, Malunion, stiffness

\section{Introduction}

Distal femur fractures account for approximately $6 \%$ of all femoral Fractures ${ }^{[1]}$. A classic bimodal distribution exist with one peak in incidence in young men (15-30 years) and elderly women (>70 years). Young patients are affected by high velocity trauma (including motor vehicle accident, motorcycle or sports injury) and elderly are predisposed to low energy fracture due to osteoporosis ${ }^{[2]}$. Intra-articular fractures of the distal femur are difficult to treat and present considerable challenges in management ${ }^{[3]}$. The open reduction and internal fixation has become the standard treatment in the recent years with good results being obtained with locking compression plate ${ }^{[4]}$. Multiple surgical approaches have been described previously to obtain a good exposure of distal femoral articular surface, including medial parapatellar approach ${ }^{[5]}$, lateral para-patellar (anterolateral) approach ${ }^{[6]}$, tibial tubercle osteotomy [7, 8] and combined medial and lateral approaches ${ }^{[9]}$. The latter two approaches are too extensive and frequently lead to complications, such as delayed wound healing, flap necrosis and delayed healing of osteotomy. The parapatellar approaches provide a sufficient articular exposure but involve splitting of the quadriceps mechanism, which may lead to scarring or adhesions. Moreover, they are difficult to extend proximally, if open compression plating of the extra- articular fracture is planned. The proximal extension of a medial parapatellar approach, as described by Henry ${ }^{[10]}$ involves cutting through the rectus tendon, which may not be desirable. Recently, Starr et al. ${ }^{[11]}$ described a modified anterior "swashbuckler" approach to the distal femur, which facilitated complete exposure of distal femur articular surface and quicker rehabilitation. 


\section{Aims and objectives}

To evaluate and compare the functional and radiological outcome of patients treated with modified anterior approach (Swashbuckler approach) and lateral approach for management of distal femur fractures.

\section{Materials and methods}

This prospective study was conducted at a tertiary health care center Dr. Bhim Rao Ambedkar Memorial Hospital, Raipur, Chhattisgarh after approval by the Institutional ethical committee. The study included 60 patients with supracondylar fracture of femur with intra articular extension who underwent open reduction and internal fixation (ORIF) with Distal femur locking compression plate (DF- LCP) either by standard lateral approach (Group A) or Modified anterior approach (Swashbuckler approach- Group B). All cases were performed under spinal anesthesia in supine position with a roll or triangle under the operating knee. The patients were followed up at 6 weeks, 12 weeks, 24 weeks and 12 months after surgery.

\section{Inclusion criteria}

1. Adult patients with age above 18years.

2. Closed Supracondylar fracture of femur with intraarticular extension (AO type B and C).

3. Patients giving informed written consent.

\section{Exclusion criteria}

1. Supracondylar fracture AO type A (Extra-articular).

2. Open fracture.

3. Pathological fracture.

4. patients presenting after 3 weeks.

5. Patients with other associated skeletal injury.

6. Patients with associated head injury or severe life threatening medical problems.

7. Patients who were bedridden or non ambulatory.

\section{Lateral Approach ${ }^{[12]}$}

The incision is made directly laterally in the thigh and through the midpoint of the lateral condyle distally while staying anterior to the proximal insertion of the lateral collateral ligament. Proximally, the incision is extended as necessary for diaphyseal involvement of the supracondylar fracture. The distal incision can be extended so that it gently curves from the knee joint axis anteriorly to the lateral border of the tibial tubercle when the fracture involves the articular condyles. The fascia lata is incised in line with the skin incision, and its fibers are split. Distally, it is often necessary to incise the anterior fibers of the ilio-tibial tract, and the incision is then carried down through the capsule and synovium on the lateral aspect of the lateral femoral condyle. Care must be taken to identify the superior lateral geniculate artery, which must often be ligated, and to avoid damage distally to the lateral meniscus. Visualization of the articular surfaces of the lateral condyle is usually adequate. The medial condyle, especially its posteromedial aspect, is difficult to visualize. To expose the distal femoral shaft, the vastus lateralis muscle must be reflected off the lateral inter muscular septum. Care must be taken to identify and ligate the perforating vessels.

\section{Swashbuckler Approach ${ }^{[11]}$}

In supine position with a roll under knee, make a midline incision from above the fracture laterally to across the patella. Extend the incision directly down to the fascia of the quadriceps. Incise the quadriceps fascia in line with the skin incision. Sharply dissect the quadriceps fascia off the vastus lateralis muscle laterally to its inclusion with the iliotibial band. Retract the iliotibial band and fascia laterally, continuing the dissection down to the linea aspera. Incise the lateral parapatellar retinaculum, separating it from the Vastus lateralis. Make a lateral parapatellar arthrotomy to expose the femoral condyles. Place a retractor under the vastus lateralis and medialis, exposing the distal femur and displacing the patella medially. Ligate the perforating vessels, and elevate the vastus lateralis, exposing the entire distal femur.

\section{Post-operative care}

1. Patients were kept nil orally 4 to 6 hours post operatively.

2. IV fluids/blood transfusions were given as needed.

3. Analgesics were given according to the needs of the patient

4. The limb was kept elevated over a BB splint.

5. IV antibiotics were continued for 7 days and switched over to oral antibiotics on the 7th day and continued till the 14th day.

6. Post operatively after 48 hours-Wound Inspection, drain removal, Check X-ray to assess reduction.

7. Quadriceps exercises, range of movement and hamstring exercises were started on First post-operative day depending on fixation, stability and fracture configuration.

8. Sutures were removed on the 14 th postoperative day and patients were discharged.

9. Patients were called for periodic follow up at 6 weeks, 12 weeks, 24 weeks and 12 months for clinical and radiological assessment.

\section{Follow-up}

On follow up, all patients were assessed using Neer's Criteria for functional outcome ${ }^{[13]}$. It consists of Functional (70 units) and Anatomic (30 units) factors. The results were evaluated by taking into consideration the following factors:
1. Pain -20 points
2. Function -20 points
3. Motion -20 points
4. Work -10 points
5. Gross Anatomy -15 points
6. Roentgenograms -15 points

\begin{tabular}{|c|c|}
\hline \multicolumn{2}{|c|}{ Neer's score over all ratting } \\
\hline Excellent & Above 85 \\
\hline Good & $70-85$ \\
\hline Fair & $55-69$ \\
\hline Poor & Below 55 \\
\hline
\end{tabular}

\section{Results}

There were 55 (91.67\%) males and 5(8.33\%) females in our study. The age group ranged from 18-65 years, with a mean age of 36.01 years. Predominant lower limb involved was right side accounting for 44 cases (73.3\%) and remaining 16 cases $(26.7 \%)$ were left sided. There were 50\% AO type C3 and $41 \% \mathrm{AO}$ type $\mathrm{C} 2$ fractures. This pattern confirms to the high velocity injuries being commonly associated with $\mathrm{AO}$ type $\mathrm{C}$.

All cases were performed under spinal anesthesia either SAB or CSE. The mean duration of surgery for lateral approach group (99.6min) was greater than Swashbuckler group (85 min). The average time to union was 3.66 months (14.64 weeks) with a range of $3-5$ months (12-20 weeks). Mean Neer's score was 81.83 and standard deviation 11.16 in 
swashbuckler group compared to 76.96 Neer's score and standard deviation 8.54 in lateral approach group. Excellent results were seen in 19 cases $(63.3 \%)$ in swashbuckler group as compared to 13 cases $(43.3 \%)$ in lateral approach group. Total of $13(21.6 \%)$ patients encountered some kind of local complication (Table -6). Higher complication rate was noted in Lateral approach group in our study.
Table 1: Age Distribution

\begin{tabular}{|c|c|c|c|}
\hline \multirow{2}{*}{ Age Group (Years) } & \multicolumn{3}{|c|}{ No Of Patients } \\
\cline { 2 - 4 } & Group A & Group B & Total (A+B) \\
\hline $18-30$ & 11 & 15 & 26 \\
\hline $31-40$ & 9 & 3 & 12 \\
\hline $41-50$ & 8 & 7 & 15 \\
\hline $51-60$ & 1 & 5 & 6 \\
\hline $61-70$ & 1 & - & 1 \\
\hline Total & 30 & 30 & 60 \\
\hline
\end{tabular}

Table 2: Sex Distribution

\begin{tabular}{|c|c|c|c|c|c|c|}
\hline \multirow{2}{*}{ Sex } & \multicolumn{3}{|c|}{ No Of Patients } & \multicolumn{3}{c|}{ Percentage Of Patients } \\
\cline { 2 - 7 } & Group A & Group B & Total (A+B) & Group A & Group B & Total (A+B) \\
\hline Male & 26 & 29 & 55 & 86.67 & 96.67 & 91.67 \\
\hline Female & 4 & 1 & 5 & 13.33 & 3.33 & 8.33 \\
\hline
\end{tabular}

Table 3: Fracture Pattern Distribution

\begin{tabular}{|c|c|c|c|c|c|c|}
\hline \multirow{2}{*}{ Ao Type } & \multicolumn{3}{|c|}{ No Of Patients } & \multicolumn{3}{c|}{ Percentage Of Patients } \\
\cline { 2 - 7 } & Group A & Group B & Total (A+B) & Group A & Group B & Total (A+B) \\
\hline B1 & 1 & 1 & 2 & 3.33 & 3.33 & 3.33 \\
\hline B2 & 2 & - & 2 & 6.67 & - & 3.33 \\
\hline B3 & 0 & - & 0 & - & - & - \\
\hline C1 & 1 & - & 1 & 3.33 & 0 & 1.67 \\
\hline C2 & 16 & 9 & 25 & 53.33 & 30 & 41.67 \\
\hline C3 & 10 & 20 & 30 & 33.33 & 66.67 & 50.00 \\
\hline
\end{tabular}

Table 4: Duration of Surgery in Minutes

\begin{tabular}{|c|c|c|c|c|c|c|}
\hline \multirow{2}{*}{ Minutes } & \multicolumn{3}{|c|}{ No Of Patients } & \multicolumn{3}{c|}{ Percentage Of Patients } \\
\cline { 2 - 7 } & Group A & Group B & Total (A+B) & Group A & Group B & Total (A+B) \\
\hline 60-90 Min & 13 & 20 & 33 & 43.33 & 66.67 & 55.00 \\
\hline 90-120 Min & 11 & 10 & 21 & 36.67 & 33.33 & 35.00 \\
\hline >120 Min & 6 & 0 & 6 & 20.00 & 0.00 & 10.00 \\
\hline
\end{tabular}

Table 5: Union Time

\begin{tabular}{|c|c|c|c|c|c|c|}
\hline \multirow{2}{*}{ Duration In Months } & \multicolumn{3}{|c|}{ No Of Patients } & \multicolumn{3}{c|}{ Percentage Of Patients } \\
\cline { 2 - 7 } & Group A & Group B & Total (A+B) & Group A & Group B & Total (A+B) \\
\hline < 3 MONTH & 9 & 13 & 22 & 10.00 & 23.33 & 16.67 \\
\hline 3-6 MONTH & 21 & 17 & 38 & 70.00 & 56.67 & 63.33 \\
\hline > 6 MONTH & 0 & 0 & 0 & 0.00 & 0.00 & 0.00 \\
\hline
\end{tabular}

Table 6: Complications

\begin{tabular}{|c|c|c|c|c|c|c|}
\hline \multirow{2}{*}{ Local Complications } & \multicolumn{3}{|c|}{ No Of Patients } & \multicolumn{3}{c|}{ Percentage Of Patients } \\
\cline { 2 - 7 } & Group A & Group B & Total (A+B) & Group A & Group B & Total (A+B) \\
\hline Restriction Of Movement & 4 & 2 & 6 & $13.33 \%$ & $6.66 \%$ & $10 \%$ \\
\hline Terminal Extension Lag & 2 & 2 & 4 & $6.66 \%$ & $6.66 \%$ & $6.66 \%$ \\
\hline Superficial Infection & 2 & 0 & 2 & $6.66 \%$ & 0 & $3.33 \%$ \\
\hline Chronic Swelling Of Limb & 1 & 0 & 1 & $3.33 \%$ & 0 & $1.67 \%$ \\
\hline Total Complication & 9 & 4 & 13 & $30 \%$ & $13.33 \%$ & $21.66 \%$ \\
\hline No Complications & 21 & 26 & 47 & $70 \%$ & $86.66 \%$ & $78.33 \%$ \\
\hline
\end{tabular}

Table 7: Neer's Score Result

\begin{tabular}{|c|c|c|c|c|c|c|}
\hline \multirow{2}{*}{ Neer Functional Score } & \multicolumn{3}{|c|}{ No Of Patients } & \multicolumn{3}{c|}{ Percentage Of Patients } \\
\cline { 2 - 7 } & Group A & Group B & Total (A+B) & Group A & Group B & Total (A+B) \\
\hline Excellent & 13 & 19 & 32 & $43.30 \%$ & $63.30 \%$ & $53.30 \%$ \\
\hline Good & 13 & 6 & 19 & $43.30 \%$ & $20 \%$ & $33.30 \%$ \\
\hline Fair & 4 & 5 & 9 & $13 \%$ & $16.7 \%$ & $15 \%$ \\
\hline
\end{tabular}

\section{Discussion}

Fractures in the distal femur have posed considerable therapeutic challenges throughout the history of fracture treatment. Most of these surgical failures were due to inadequate fixation of the fracture fragments ${ }^{[14]}$. The aim of treatment is to achieve anatomical reduction of articular surface, restoration of the limb length and alignment, as well as allowing for early limb mobilization to avoid articular stiffness and the loss of the muscle mass. Good planning and execution of surgery in complex $\mathrm{C} 3$ distal femur fractures results in better functional outcomes on par with other means of fixation even in these intra articular injuries. Reconstruction of distal femur fractures especially in supracondylar and intercondylar fractures is a challenging 
task. The prognostic factors for supracondylar fracture included age, intra-articular involvement, methods of treatment, timing of joint motion, etc (Morre 1987) ${ }^{[15]}$. The present study does not show a biphasic age distribution of the patient population as seen in studies ${ }^{[11]}$. This is a reflection of the mechanism of injury which was high energy trauma in $100 \%$ of our patients of which most of whom were younger. The reason being that, in male patients there was more outdoor activities, so they were more prone to vehicular accident and majority females being house wives were less exposed to road traffic accidents. In our study of 60 patients, 93\% were type C fracture and only $7 \%$ belonged to type B fractures. This signifies that most of the distal femoral fractures are caused by high energy trauma ${ }^{[16]}$. They are associated with severe comminution and are unstable.

Local complications were present in $15 \%$ of our patients. They included restriction of movements in 6 patients, chronic swelling of injured lower limb in 1, and superficial infection in one patient. Daroch et al. ${ }^{[3]}$, reported superfecial infection in 2 patients along with 1 implant failure and 1 delayed union as local complication in their study.

The average time to union was 3.66 months with a range of 3 - 5 months. Successful fracture union was defined as complete bridging callus in three cortices, together with painless full weight bearing. Radiological union of the fracture i.e. characterized by cortex to cortex healing and bridging callus of the fracture in both AP and lateral views of follow up x-rays, was considered as satisfactory union. Time to union in Type $\mathrm{C}$ fractures generally was found to be longer compared to Type B fractures. There was significant delay in union rate and considerable decrease in post op knee movements if surgery was delayed $>2$ weeks.

We found that time to union in distal femoral fractures are generally longer than usual fracture union due to high incidence of communition and osteoporosis. Type $\mathrm{C}$ fractures took longer time to unite compared to Type B fractures. Similarly Schatzker and Lambert ${ }^{[17]}$ in 1979 obtained $76 \%$ to $86 \%$ union in patients with fracture of distal femur.

Infection rate in our study was $6.67 \%$ which was similar to the finding by Yeap and Deepak ${ }^{[16]}$.

Sanders ${ }^{[18]}$ et al. In our study, the mean flexion was $92.33^{0}$ (range $30^{\circ}-135^{\circ}$ ). Mean flexion in swashbuckler group was 100.83 compared to 83.83 in lateral group. As most of the fractures were complex intra articular AO type C3, better range of movement was achieved in patients treated with DFLCP by swashbuckler approach. At the same time strict postop physiotherapy including CPM and clinical experience plays an important role in functional out come.

Using Neer's scoring in the study, 32 patients $(53.3 \%)$ had excellent results, 19 cases $(33.3 \%)$ good results and 9 cases $(15 \%)$ had fair results. Excellent and good results accounted for $81.7 \%$ of cases and remaining $18.3 \%$ included fair cases. Excellent results were seen in 19 cases $(63.3 \%)$ in swashbuckler group B as compared to 13 cases $(43.3 \%)$ in lateral approach group $\mathrm{A}$ which was significant. This difference can be attributed to better anatomical reduction and exposure in Swashbuckler group as compared to lateral approach group.

\section{Conclusion}

Reconstruction of distal femur fractures especially in supracondylar and intercondylar fractures is a challenging task. For a better functional outcome proper anatomical restoration and alignment is required which can be achieved by swashbuckler approach as proper exposure of joint is possible to reconstruct the articular surface. From our study we conclude that Swashbuckler approach gives better results in terms of anatomical reduction and functional outcome for AO C3 fractures however for AO C2 type fractures, similar results were obtained with both approaches.

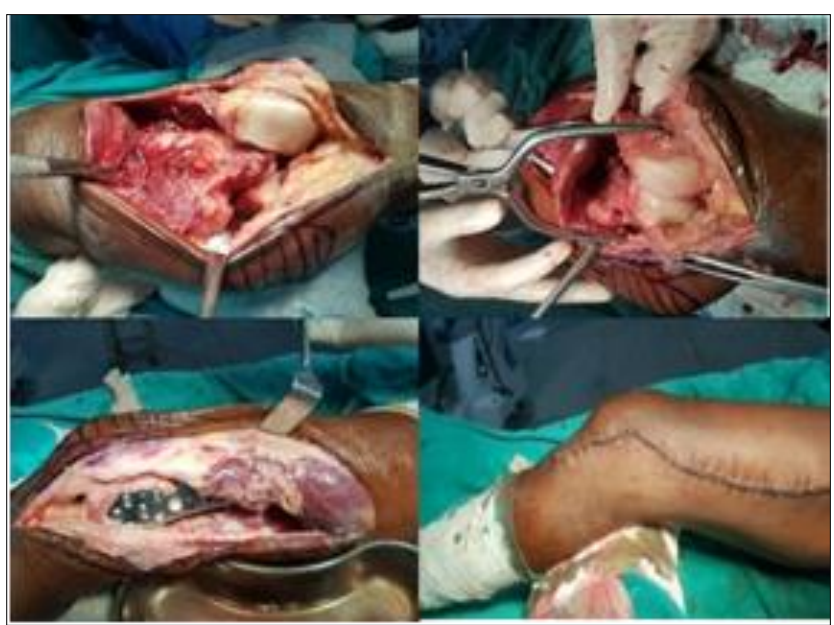

Fig 1: Intraoperative photographs (Swashbuckler approach)

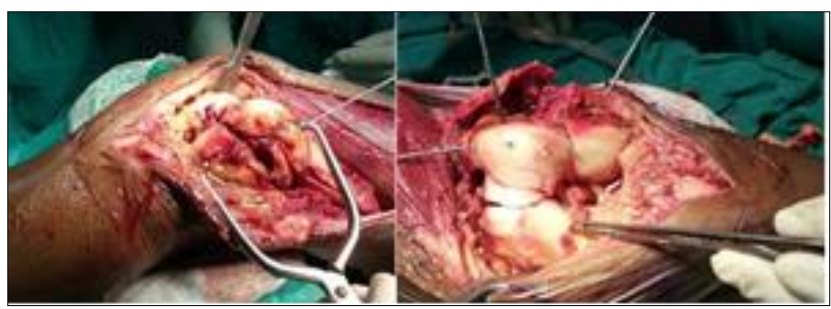

Fig 2: Intraoperative photographs (Swashbuckler approach)

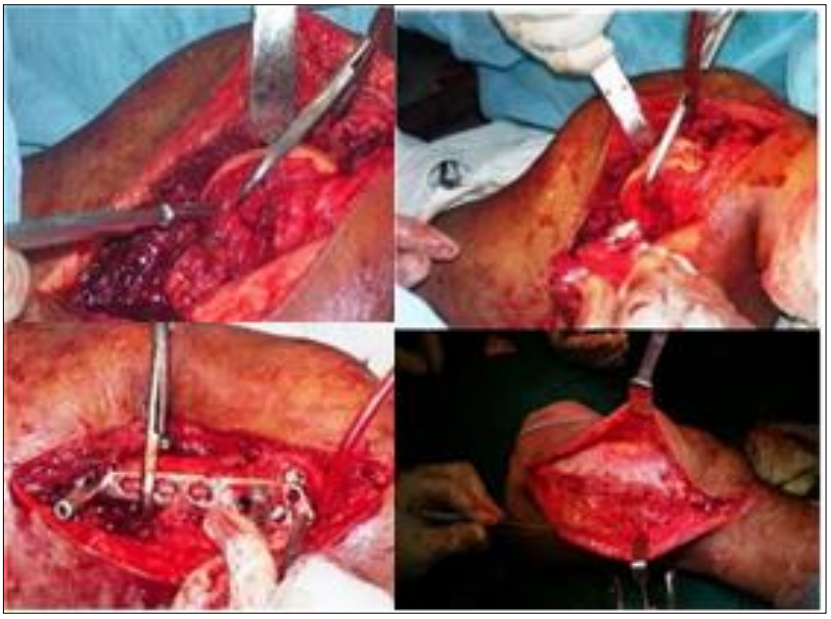

Fig 3: Intraoperative photographs (Lateral approach)

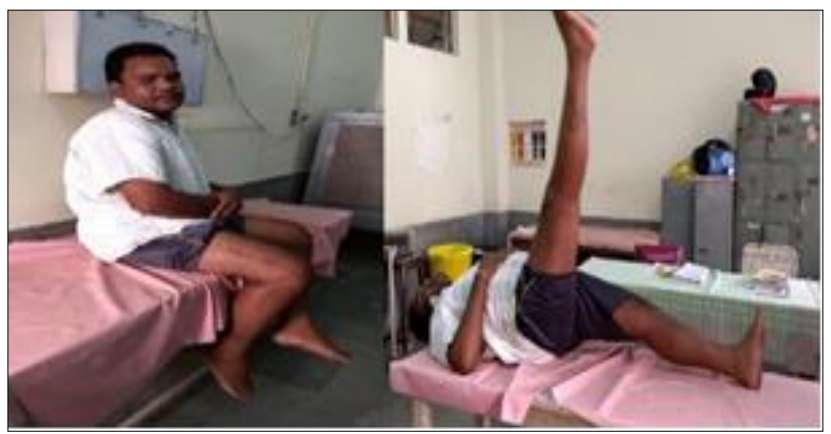

Fig 4: 6 months follow-up clinical photograph 

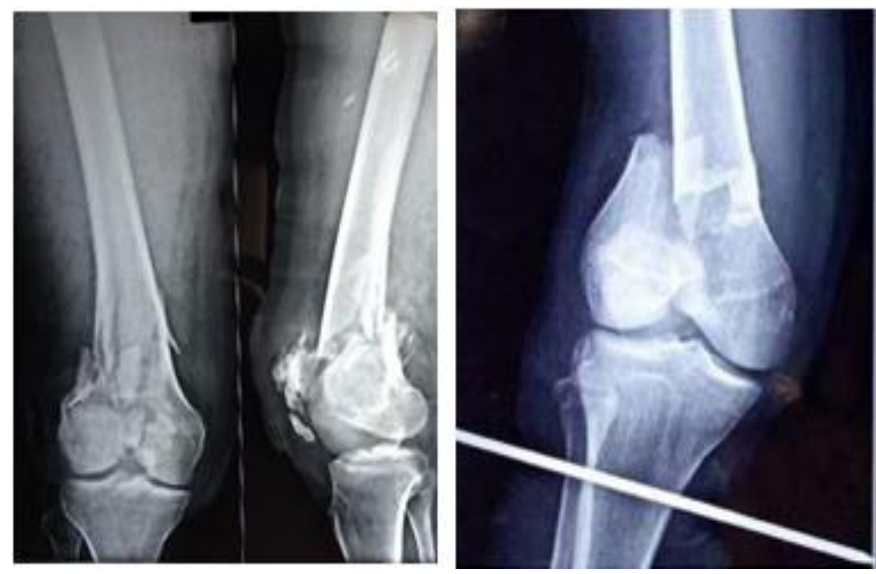

Fig 5: Preoperative radiograph
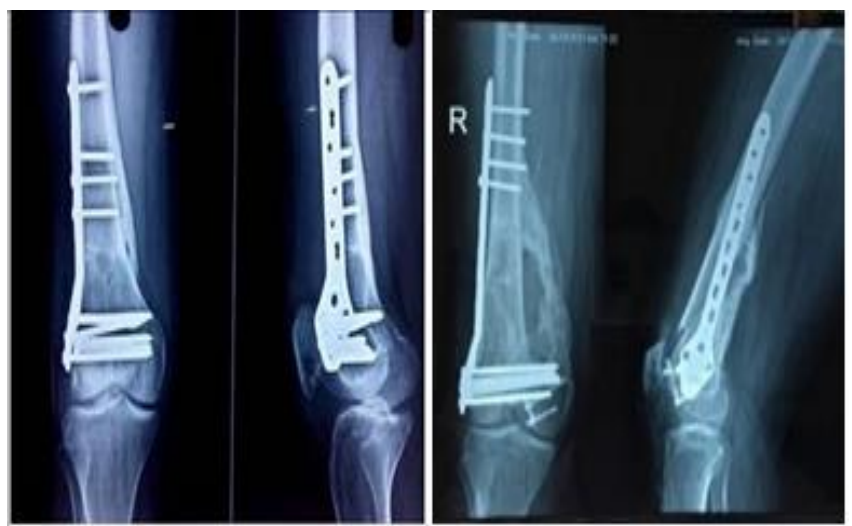

Fig 6: Postoperative radiograph

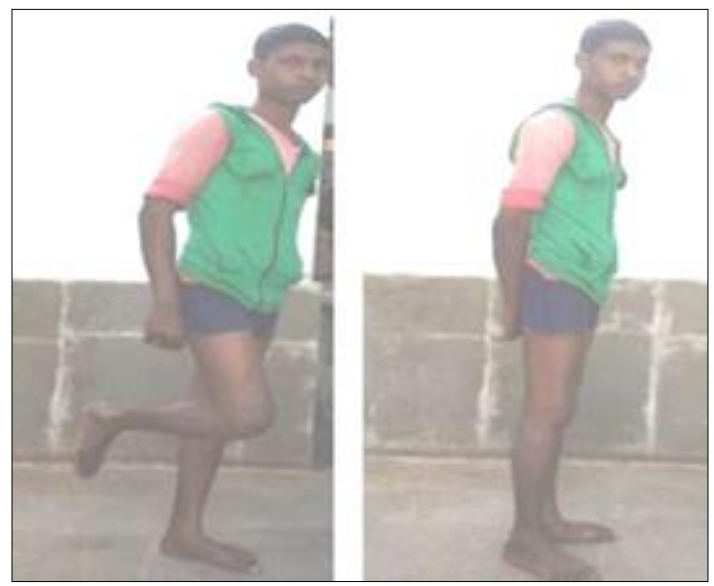

Fig 7: 6 months follow-up clinical photograph

\section{References}

1. Martinet Cordey J, Harder Y. The epidemiology of fractures of the distal femur. Injury. 2000; 31(3):C62-3.

2. Singer BR, McLauchlan GJ, Robinson CM. Epidemiology of fractures in 15000 adults: The influence of age and gender. J Bone Joint Surg Br. 1998; 80:243-8.

3. Manjit SD, Vashisht D, Sreen S. Management of intraarticular fracture of distal femur with LCP and Lag screws in adults. International Journal of Research in Medical Sciences. 2017; 5(4):1434-38.

4. Ehlinger M, Ducrot G, Adam P, Bonnomet F. Distal femur fractures. Surgical techniques and a review of literature. Orthop Traumatol Surg Res. 2013; 99(3):35360.

5. Schatzker J. Fractures of the distal femur revisited. Clin Orthop Relat Res. 1998; 347:43-56.
6. Krettek C, Schandelmaier P, Miclau T, Bertram R, Holmes W, Tscherne H. Trans articular joint reconstruction and indirect plate osteosynthesis for complex distal supracondylar femoral fractures. Injury. 1997; 28(1).

7. Khalil AES. Highly unstable complex C3-type distal femur fracture: Can double plating via a modified Olerud extensile approach be a standby solution? J Orthop Traumatol. 2012; 13:179-88.

8. Olerud S. Operative treatment of supracondylar Condylar fractures of the femur. Technique and results in fifteen cases. J Bone Joint Surg Am. 1972; 54:1015-32.

9. Lin D, Chen C, Lian K, Zhai W. Treatment of type C3.3 distal femoral fractures with double-plating fixation via U-shaped incision. Zhongguo Xiui. 2010; 24:683-6.

10. Henry AK. Extensile Exposure. Edinburgh: Livingstone; 1959, 199.

11. Starr AJ, Jones AL, Reinert CM. The swashbuckler: A modified anterior approach for fractures of the distal femur. J Orthop Trauma. 1999; 13:138-40.

12. Hoppenfeld S, deBoer P. The femur. Surgical Exposures in Orthopaedics. The 182 Anatomic Approach, Philadelphia: J.B. Lippincott, 1984, 357-387.

13. Neer CS II, Grantham SA, Shelton ML. Supracondylar Fracture of the Adult Femur - A Study of One Hundred and Ten Cases. JBJS Am. 1967; 49(4):591-613.

14. Mize RD, Bucholz RW, Grogan DP. Surgical treatment of displaced, comminuted fractures of the distal end of the femur. J Bone Joint Surg Am. 1982; 64:871-879.

15. Moore TJ, Watson $\mathrm{T}$, Green SA. Complications of surgically treated supracondylar fractures of the femur. J Trauma. 1987; 27:402-406.

16. EJ Yeap. Distal Femoral Locking Compression Plate Fixation in Distal Femoral Fractures, Malaysian Orthopaedic Journal. 2007; 1(1).

17. Schatzker J, Lambert DC. Supracondylar fractures of the femur. Clin Orthop. 1979; 138:77-83.

18. Sanders R, Swintkowski M, Rosen H. Double-plating of comminuted, unstable distal femur fracture. The Comprehensive Classification of Fractures of Long Bones. New York, Springer-Verlag, 1990. 